\title{
İşletmelerin Stratejik Yönetiminde Sosyal Ekonomik Ăgların Önemi
}

\section{The Importance of Social Economic Networks For Strategic Management of Enterprises}

\author{
Alper Bahadır Dalmış a,* \\ ${ }^{a}$ Arş. Gör. Dr., Türk Hava Kurumu Üniversitesi, İşletme Fakültesi, İşletme Bölümü, 06790, Ankara/Türkiye. \\ ORCID: 0000-0002-9069-3917
}

\section{MAKALE BILGIISI}

\section{Makale Geçmişi:}

Başvuru tarihi: 25 Nisan 2018

Düzeltme tarihi: 12 Haziran 2018

Kabul tarihi: 19 Temmuz 2018

Anahtar Kelimeler:

Stratejik Yönetim

A $\breve{g}$ Toplum Modeli

Siber Kültür

Sosyal Ekonomik Ağlar

\section{ART ICLE INFO}

\section{Article history:}

Received April 25, 2018

Received in revised form June 12, 2018

Accepted July 19, 2018

\section{Keywords:}

Strategic Management

Network Society Model

Cyber Culture

Social and Economic Networks
ÖZ

Günümüzde sınırsız sayı ve içerikteki iletişim olanaklarıyla "ağların ağı” olarak nitelenen internet üzerinden kurulan sosyal ağların kullanımı küresel düzeyde yaygınlaştıkça, bu tür iletişim ağlarına ekonomik ağlar da eklemlenmiştir. Böylece internet insanlık tarihinde şimdiye kadar görülmemiş tarz ve içerikte yeni "sosyal ve ekonomik ilişkileri" gündeme getirmeye başlamış; geleneksel ekonomilerde yüzyıllardır benzer şekilde tanımlanan yönetim, satış, talep, arz, fiyat, pazarlama vb. konularla ilişkili tüm klasik kuramlar yeni ortaya çıkan "sosyal ve ekonomik ağlar" içerisinde yeniden tanımlanmaya başlanmıştır. Temel amacı strateji oluşturma sürecinde sosyal ve ekonomik ağlara odaklanmanın anlam ve önemini ortaya koymak olan bu araştırma kapsamında, 21.yüzyılda sosyo-ekonomik alanlarda yaşanan değişim ve dönüşümleri açıklayan paradigmalar çerçevesinde sosyal ve ekonomik ağ odaklı strateji oluşturma süreçleri incelenmeye çalışılııştır.

\section{A B S T R A C T}

Today, as the use of social networks established on the internet, which is described as "network of networks" with the unlimited number and content communication possibilities, spreads at the global level, economic networks are also added to such communication networks. Thus, the internet has begun to bring "new kinds of social and economic relations" to the agenda in a way that has never been witnessed before. In the traditional economies, similarly defined classical theories for ages related to management, sales, demand, supply, price, marketing, etc. have been redefined within the emerging "social and economic networks." In the context of this research, which focuses on the significance of focusing on social and economic networks in the process of creating a core strategy; social and economic network-oriented strategy-making processes have been tried to be examined within the framework of paradigms that explain the changes and transformations experienced in the socio-economic areas in the 21 st century.

\section{Giriş}

Stratejik yönetim, günümüz işletmelerinin etkili, yenilikçi, kaliteli ve rekabet üstü niteliklerde üretim yapmalarını sağlamak amacıyla ve sürekli değişen çevresel koşullara uyum içinde yönetilmesi esasına dayanan, post-modern çağa özgü bir yönetim yaklaşımıdır.

Stratejik yönetim bir işletmenin hangi sektörde olursa olsun en önemli kabiliyetlerini ortaya koyarak, rekabet gücünü arttıran faktörlerden nasıl yararlanılabileceğini önceden belirlemek suretiyle, işletmenin geleceğe ve çevresel değişimlere karşı hazırlıklı olmasını sağlayacaktır (Bayrak,
2013: 12). Esasen işletme ve çevresi arasındaki ilişkileri düzenleyip, rakiplere karşı üstünlük ve avantaj kazanabilmek amacıyla, kıt örgütsel kaynakların etkin ve verimli kullanılmasını öneren stratejik yönetim, gelecek odaklı, inovatif, kaliteli ve etkili stratejilerden oluşarak geliştirilmektedir (Akgemici, 2015: 9).

Dolayısıyla günümüzde rekabet üstü olmak ve sektöründe marka değerlerini yükseltmek isteyen tüm işletmeler sosyal ve ekonomik ağlarda yaşanan gelişmeleri stratejik yönetim anlayışı çerçevesinde ele almaya çalışmaktadır. Özellikle küresel ölçekli büyük işletmelerin sosyal ağlar üzerinden pazar paylarını arttırma, marka değerini yükseltme, ürün ve

\footnotetext{
* Sorumlu yazar/Corresponding author.

e-posta: abdalmis@thk.edu.tr
} 
hizmetlerini tanıtmanın yanı sıra, bu ağlar üzerinden yeni modaları, tarzları, talepleri, üretim ve tüketim kalıplarını geliştirmenin yollarını aramaktadırlar (Hemsley ve Mason, 2013: 168).

İşte sosyal ve ekonomik ağlarda yaşanan rekabetin sürekli şiddetlenmesi, her geçen gün rakiplerin sayısının artması ve sürekli teknolojik gelişmelere bağlı olarak işletmelerin çevresel dönüşümlere ayak uydurma zorunda kalması gibi nedenlerle sosyal ve ekonomik ağlar stratejik yönetimin öncelikli ilgi alanına girmiştir.

Nitel araştırma kapsamında literatür incelendiğinde stratejik yönetim ve sosyal ekonomik ağlar ayrı ayrı konular dahilinde anahtar kelimeler olarak belirlenerek araştırma yapılmıştır. Anahtar kelimeler ile bulunan makaleler konuyla ilişkisi bağlamında değerlendirilmiştir. İlişkisi bulunan makaleleri daha derinden inceleyerek strateji ve sosyal ekonomik ağlar arasındaki ilişki tespit edilmeye çalışılmıştır.

Temel amacı örgütlerin strateji oluşturma sürecinde sosyal ve ekonomik ağlara odaklanmanın anlam ve önemini dikkat çekmek olan bu araştırmada, günümüz rekabet ortamında rekabet üstünlüğü sağlama ve bunu elinde bulundurabilmesi için siber kültürün stratejik yönetimdeki yeri vurgulanmak istenmiştir.

$\mathrm{Bu}$ araştırmada öncelikle strateji ve stratejik yönetim kavramları tanımlandıktan sonra, 21.yüzyılda sosyoekonomik alanlarda yaşanan değişim ve dönüşümleri açıklayan paradigmalar aşağıdaki başlıklar altında incelenmiştir.

\section{Strateji Kavramı ve Stratejik Yönetim}

Latince'deki "Stratum" sözcüğünden türeyen "Strateji" sözcüğünün askeri terminolojiden günlük yaşama ve akademik literatüre geçtiğine ilişkin yaygın bir kanaat bulunmaktadır (Güçlü, 2003: 66).

Askeri literatürde strateji kavramı, düşman karşısında daha üstün ve iyi bir konuma geçmek amacıyla mevcut savaş güç ve kaynaklarını daha etkili kullanmayı ifade etmektedir (Şentürk, 2005: 16; Acar, 2007: 6). Kavram ilk defa sosyal bilimler alanında ise 20.yüzyılın ilk yarısında İktisatçı Oskar Morgenstern tarafindan kullanıldığında da "düşmanların" yerini "rakipler" almak suretiyle kavramın benzer anlamda ve şekilde kullanıldığı söylenebilir (Aktaran: Güçlü, 2003: 68).

Tablo 1. Strateji Tanımları

\begin{tabular}{lll}
\hline & Tanımlar & Kaynakça \\
\hline & $\begin{array}{l}\text { Strateji, işletmelerin sahip } \\
\text { olduğu kıt kaynakları iç ve dış } \\
\text { çevresinde yaşanan değişimleri } \\
\text { analiz etmek suretiyle geleceği } \\
\text { öngörerek etkili bir şekilde }\end{array}$ & $\begin{array}{l}\text { Nohutçu } \\
(2008: \text { 106) }\end{array}$ \\
kullanmasına yarayan yönetsel & \\
kararlardır & $\begin{array}{l}\text { Stratejiden, bir örgütün } \\
\text { hedeflerini başarmak için } \\
\text { izleyeceği yol ve yöntemleridir. }\end{array}$ & Çevik (2010: \\
\cline { 2 - 2 } & $\begin{array}{l}\text { Strateji, işletmelerin kendi öz } \\
\text { kaynaklarıyla sınırlı olan üretim } \\
\text { kapasitesine ve çevresel }\end{array}$ & Güçlü (2003: \\
\hline
\end{tabular}

\begin{tabular}{|c|c|}
\hline $\begin{array}{l}\text { değişimlerle ilgili örgüt } \\
\text { yöneticilerinin etkili analiz ve } \\
\text { isabetli öngörülerine dayanan; } \\
\text { örgüt için hedef ve öncelikleri } \\
\text { belirleyerek bunların } \\
\text { uygulanmasını içeren yönetsel } \\
\text { kararları ifade etmektedir. }\end{array}$ & \\
\hline $\begin{array}{l}\text { Strateji, örgütün iç ve dış } \\
\text { çevresinde yaşanan değişimlere } \\
\text { tüm yönetsel alt sistemlerin ve } \\
\text { üretim süreçlerinin uyum } \\
\text { sağlayacak şekilde örgütsel } \\
\text { faaliyetlerini yeniden } \\
\text { düzenlenmesini sağlayan } \\
\text { yönetsel kararların toplamıdır. }\end{array}$ & $\begin{array}{l}\text { Aydin ve } \\
\text { Aksoy (2007: } \\
\text { 297) }\end{array}$ \\
\hline
\end{tabular}

O yüzden denilebilir ki, işletme yönetiminde stratejilerin varlık sebebi örgütleri verimli şekilde yönetmek, rekabet üstünlüğü kazanmak ve onları çevreye uyumunu sağlamak tir.

Dolayısıyla işletme yönetiminde stratejiden söz edilirken anlatılmak istenen bir kurumun hedeflerini başarmak için izleyeceği yol ve yöntemlerin yaşanan gelişmelere ve oluşan yeni toplumsal ve endüstriyel anlayışlara göre üretim süreçlerini yeniden yapılandırılmasını sağlayacak nitelikteki yönetsel kararlar anlatılmaktadır (Çevik, 2010: 138). Böyle bir anlayışla geliştirilen stratejiler günümüz toplumlarının benimsediği çizgide üretim yapma ve ürettiğini pazarlama konusunda işletmelerin etkinliğini arttıracaktır (Efil, 2011).

Öte yandan literatürde strateji kavramının bir durum analiz aracı, amaçlarla ilgili olma, çevresi ile ilişkileri düzenleme, günlük rutin işlerin aksine gelecek için yol haritası sunma, insan gücü ve finansal kaynakları ahenk içerisinde yönetme ve harekete geçirme, faaliyet alanlarını komplike ve hareketli bir çevrede belirleme, çalışanları işlerine motive etme özelliklerini barındırdığından bahsedilmektedir (Murat ve Bağdigen, 2008: 47-48). Ayrıca strateji; üst yönetimin fonksiyonu olma özelliği taşımakta olup büyük oranda üst düzey yöneticilerin yetki ve sorumluluğu alanında yer almaktadır (Koçel, 2011: 24).

Strateji kavramının kendine özgü diğer bir karakteristik özelliği ise bu olgunun hem amaç ve hem sonuç odaklı olmasıdır (Ülgen ve Mirze, 2013: 36). Günümüz işletmelerinin üretim sürecindeki başarısı üzerinde oldukça etkili bir değişken olarak bilinen stratejiler, aslında örgütlerin tüm teknolojik, finansal ve finansal olmayan sermayesinin etkili bir şekilde yönetilmesi açısından en önemli yönetsel kararlar olduğu söylenebilir (Murat ve Bağdigen, 2008: 49).

$\mathrm{Bu}$ bağlamda stratejiler işletmelerde her gün yapılan rutin işlere yönelik alınan kararlardan ziyade, geleceği öngörme iddiası taşıyan ve örgütün uzun dönemli yaşamına devam edip etmemesini de bir anlamda belirleyen gelecek odaklı kararlardan oluşmaktadır. O yüzden denilebilir ki strateji gelecek odaklıdır ve gelecekteki belirsizliği azaltarak, izlenmesi gereken yolları ve kuralları şimdiden açıklığa kavuşturmaktadır (Koçel, 2011: 25).

Literatürde stratejik yönetim, İşletmelerin verimlilik, etkililik, hizmet kalitesi ve rekabetlerini koruyabilmeleri amacıyla sürekli değişen, dinamik, karmaşık çevresel koşullara uyum sağlamaları suretiyle stratejik olarak 
yönetilmesini benimseyen post-modern bir yönetim yaklaşımıdır (Barca ve Nohutçu, 2008: 337).

Literatüre bakıldığında stratejik yönetim kavramının işletme ve çevresi arasındaki ilişkileri düzenlemek, rakiplere karşı üstünlük ve farkındalık kazanabilmek için, her türlü örgütsel kaynağın etkin ve verimli kullanılması amacıyla geleceğin şimdiden öngörülmesini esas alan post-modern bir yönetim tarzıdır (Akgemici, 2015: 9). Başka bir tanıma göre stratejik yönetimin işletme hedef ve amaçlarına en etkili yolla ulaşılmasını mümkün kılacak kararların alınmasını, uygulanmasını ve değerlendirilmesini önceleyen gelecek odaklı bir yönetim yaklaşımı şeklinde bu kavramı tanımlamayı tercih etmektedir (Güçlü, 2003: 74).

Daha basit bir tanımlamayla nasıl ki yönetim başkaları vasıtasıyla iş görme sanatı ise, aynı şekilde stratejik yönetim de örgütlerin geleceği için bugünden iş görmeye başlaması anlamına geldiğini söylemek mümkündür (Gül ve Kırılmaz, 2013: 25).

Görüldüğü üzere literatürde stratejik yönetimin ne olduğuna ilişkin birçok tanımlama bulunmaktadır. Her ne kadar tanımlar çeşitli olsa da, tanımların ortak noktasına göre stratejik yönetimle ilgili bu araştırma kapsamında şöyle bir tanımlama yapmak mümkündür: Stratejik yönetim işletmelerin geleceği öngörme kapasitelerine göre sistematik bir planlamayla belirledikleri stratejiler geliştirerek tüm örgütsel süreçlerin bu stratejilere göre yönetilmesine olanak tanıyan yenilikçi, etkili, katılımcı ve esnek bir yönetim yaklaşımıdır (Doğan, 2011: 69).

Literatürde stratejik yönetim anlayışını, klasik yönetim anlayışından ayıran üç temel karakteristik özelliğine vurgu yapıldığı görülmektedir. Bunlar stratejik yönetimin gelecek yönelimli olması, rekabet avantajı yaratması ve ortalama üzerinde getiriye odaklanarak bütüncül bakış açısıyla yönetsel süreçlere yaklaşması şeklinde sıralanabilir (Bayrak, 2013: 12).

Ayrıca stratejik yönetimin temelinde bir işletmenin hem güçlü hem de zayıf yönlerini, dış çevrede yaşanan değişimlerin ortaya çıkarttığı firsat ve tehditleri öngörerek, işletmenin tüm yönetsel süreçlerinde gereken değişim ve dönüşümleri, vakit kaybetmeksizin geliştirmek yatmaktadır (Söyler, 2007: 105). O yüzden denilebilir ki, stratejik yönetim anlayışı sürekli değişim, yenilikçilik, teknoloji ve gelişimden yana post-modern bir yönetim anlayışıdır (Narinoğlu, 2009: 122).

Literatürde stratejik yönetimin diğer bir karakteristik özelliği olarak bu anlayışın merkeziyetçi ve örgütlerdeki üst yönetimin bir fonksiyonu olduğu söylenmektedir (Güçlü, 2003: 74; Dinçer, 2013: 36). Aslında stratejik yönetim orta ve alt kademe yöneticilere de rehberlik etmekle birlikte tepe yönetimin tam desteği olmadan etkili strateji geliştirmenin pek mümkün olmayacağını söylemek mümkündür (Öztop, 2007: 19).

Ayrıca işletmelerin geleceğine yön verenler genellikle üst yönetim olduğu için stratejik yönetim daha çok üst yöneticileri ilgilendiren ve hiyerarşik olarak en tepeden başlayan, daha sonra tabana yayılarak tüm çalışanlar tarafindan desteklenen bir strateji geliştirme süreci olduğunu söylemek mümkündür (Narinoğlu, 2009: 123).
Etkili strateji geliştirme süreci olarak da ifade edilen stratejik yönetimin diğer bir özelliği de bu tür yönetim süreçlerinin son derece sistematik olmasıdır. $\mathrm{Bu}$ anlamda geliştirilen stratejiler işletmenin bütünü ile ilgilenmesinin yanında, bunları oluşturan parçaları ve alt sistemleri de kapsayan nitelikte tasarlanması gereklidir (Gül ve Kırılmaz, 2013: 26). $O$ yüzden bir işletmede stratejik yönetim anlayışı benimsenerek, uygulamaya geçildiğinde bu yönetsel sistemi oluşturan tüm yönetsel aşamaların herhangi birisinde aksama ya da erteleme yaşandığında, sistemi oluşturan diğer halkalar da bundan olumsuz yönde etkilenmektedir (Dinçer, 2013: 36).

Son olarak belirtilmelidir ki, ister kamuda isterse özel sektörde olsun, stratejik yönetim çerçevesinde çeşitli faaliyet ve uygulamalar geliştirilirken, sadece örgütün değil aynı zamanda örgütün içinde bulunduğu toplumun talepleri de göz önünde tutulmalıdır. Zira toplum olmadan işletmeler ayakta kalamazlar ve işletmeleri ayakta tutan en önemli değerin müşteriler olduğu unutulmamalıdır. O yüzden strateji yönetimin en önemli özelliğinin de toplumsal rol ve sorumluluklarını önceleyen bir yönetim alanı olduğunu söylemek mümkündür (Dinçer, 2013: 38). Buna göre stratejik yönetimin temel amacı, değişen dünya şartları ile işletmelerin bu değişen çevresel faktörler arasında uyumun sağlanması olduğu söylenebilir (Dalmış, 2014: 40).

\section{Yeni Ekonomik Çağda Stratejik Yönetimin Önemi}

Günümüzde örgütler teknolojik, ekonomik, siyasal ve sosyokültürel alanlarda küresel düzeyde yaşanan değişim ve gelişmelere bağlı olarak her geçen gün şiddetlenen bir rekabet ortamında yaşamlarını sürdürmeye çalışmaktadırlar (Koçel, 2011: 32-34).

Şüphesiz şiddetlenen rekabet ortamında sürekli rekabet üstü olmaya çalışan işletmeler eskisinden daha fazla stratejik düşünmeye çalışmakta, özellikle iç ve dış çevresine göre geliştirdikleri "stratejiler" doğrultusunda tüm üretim ve yönetim faaliyetlerini yürütmeye gayret göstermektedirler (Bayraktar ve Yıldız, 2007). Zira yaşanan dönüşümler özellikle özel sektör açısından ezici bir rekabeti beraberinde getirirken, kamu sektöründe artan vatandaş beklentileri ve değişen evrensel kamu hizmetlerini standartları stratejik yönelimleri adeta zorunlu kılmıştır (Çiftçi, 2011: 12).

Öncelikle belirtilmelidir ki, stratejik yönetim kuramı diğer yönetim kuramlarından rekabet üstünlüğünü odak noktası olarak ele alması yönüyle ayrılmaktadır. Zira modern dönem sonrası yönetim kuramlarının (durumsallık yaklaşımı, sistem yaklaşımı ve diğer post-modern yönetim yaklaşımları) hiçbirinde rekabet üstünlüğünü odak sorunsal olarak açıklama ve tahmin etme yoluna gidilmemektedir (Barca ve Hızıroğlu, 2009: 115).

Stratejik yönetime diğer yönetsel yaklaşımlara göre bu üstünlüğü kazandıran anahtar iki kavramı vardır. Bu kavramlardan ilki gelecek odaklılıktır. Zira stratejik yönetimde örgütlerin özellikle bilinmeyen geleceğine bakılarak yön tayininde bulunulmaktadır. Böylelikle Küreselleşen dünyada geleceğin belirsizliğinden ürken pek çok örgüt ortaya koydukları yönetsel stratejiler sayesinde, çeşitli tehlikelerle dolu örgütsel yaşamda bir anlamda 
geleceği planlar hale gelmiștir (Barca ve Hızıroğlu, 2009: 117).

Stratejik yönetimin anlam ve önemini ortaya koyan diğer anahtar kavram ise bu yönetim anlayışının çevre odaklı olmasından kaynaklanmaktadır. Zira tüm işletmeler ve örgütler bütün kaynaklarını ilgili çevreden almakta, üretim süreçlerinden geçirdikten sonra çevreye çıtıllar olarak geri vermektedir. Bu noktada stratejik yönetim devreye girerek işletmelerin iç ve dış çevrelerine göre üretim süreçlerini sürekli iyileştirmeyi ve bu değişimlere göre biçimlendirmeyi önerdiği için oldukça önemlidir (Özgür, 2004: 211).

Stratejik yönetim "işletmelerin kuruluş amaçları doğrultusunda sistemin en alt birimine kadar alt kademedeki yöneticilere rehberlik ettiği, stratejik düşünmeyi ön plana çıkardığı, uzun vadeli amaçlar geliştirerek işletmenin kaynaklarını en faydalı şekilde kullanılmasını göz önünde bulundurduğu için yeni ekonomik sistemin vazgeçilmez yönetsel anlayışı olarak gösterilmektedir (Dinçer, 2013: 3638; Akgemici, 2015: 10; Murat ve Bağdigen, 2008: 67). Sayılan özelliklerin stratejik yönetimin günümüzdeki anlam ve önemini anlatması açısından oldukça açık ve net olduğu söylenebilir.

Ayrıca stratejik yönetimin günümüzde çok fazla önem kazanmasındaki temel faktörlerin başında bu anlayışın günümüz ekonomik sistemin temel özelliklerine göre geliştirilmesinden kaynaklandığı söylenebilir. Zira yeni ekonomik sistemde yenilikçiliğin ve rekabetin küresel bir boyut kazanması, teknoloji alanında yaşanan hızlı değişimler, bilginin stratejik değerinin artması ve toplumların demokratik eğilimleri daha fazla benimsemesi gibi paradigmalar stratejik yönetimi zorunlu kılmaktadır (Öztop, 2007: 33).

Gerçekten de günümüzde hızla değişen ve sürekli gelişen iş dünyasında faaliyet gösteren tüm işletmelerin amaçlarına ulaşmaya yönelik kararlar almasına ve bu kararların uygulamalarına rehberlik eden stratejik yönetimin benimsenmesi, her şeyden önce işletmelerin kıt kaynaklarının etkin ve verimli kullanılmasına, zaman ve emek israfının önlenmesine katkı yaparak, günümüz konjonktüründe onun yaşamına devam etmesini mümkün kilmaktadır (Buzlu, 2014: 6).

Stratejik yönetimin anlam ve önemini ortaya koyan diğer bir özelliği ise, bu yönetim anlayışında verimlilik hedefi, yerini "etkinlik" ve "etkililik" arayışlarına bırakmasından kaynaklanmaktadır. Yani doğru iş yapmak ile işi doğru şekilde ve doğru zamanda yapmak stratejik yönetimde birbirlerine entegre edilerek üretim süreçlerinde etkililik ve etkinlik yakalanmaya çalışılmaktadır (David, 2005: 5).

Sonuç olarak stratejik yönetim işletmelere; örgütlerde değişen durumları ve geleceğe ait tasarıları önceden görme, uygulanabilecek hedeflerin belirlenmesini sağlama, sorunlara yönelik çözümlerin araştırılmasında yöneticilere yarar sağlama, bireylerin sisteme ve oluşabilecek değişimlere daha hızlı bir şekilde entegre olmasını sağlama, finansal açıdan kârlılıklarını arttırmalarını ve en önemlisi de işletmelere uzun vadeli düşünme ve görme ufku kazandırma ve örgütlerin problem önleme yeteneğinin arttırma gibi faydalar sağlar (Akgemici, 2015: 11; Murat ve Bağdigen, 2008: 74; Eren, 2015: 7; Aydemir, 2011: 68).

\section{4. İnternet Teknolojisinde Yaşanan Gelişmeler ve Siber Kültürün Doğuşu}

Milyonlarca bilgisayar kullanıcısını birbirine sanal ağlar üzerinden bağlayan ve bu yönüyle "Ağların ağı" olarak kısaca tanımlanan internet, 21.Yüzyılda yaşayan insanların yeni bilgiler tüketirken aynı zamanda yeni bilgiler üretmesine olanak sağlayan küresel bir bilgi paylaşım ve üretim ağıdır (Bhatt, 2001: 69).

Aslında yaklaşık yarım yüzyıldır var olan internet teknolojisi son on yılda o denli gelişmiştir ki bu sayede "sosyal ve ekonomik ağlar" üzerinden insanların tüm sosyal ve ekonomik aktivitelerini sürdürmelerinin bir anlamda yolu açılmıştır (Jenkins, ve Thorburn, 2004: 15). Özellikle 2004 yılında Web 2.0 teknolojisinin geliştirilmesi, daha sonra akıllı cep telefonlarının yaygın bir şekilde kullanılmaya başlanması ve son olarak uydu bağlantılı mobil iletişim ağlarının genişlemesiyle birlikte dünyada yaşayan 7 milyar insanın internet üzerinden çeşitli nedenlerle birbiriyle iletişime geçmesi mümkün hale gelmiştir (Kuyucu, 2015: 146-147).

İşte insanlık tarihinde bütün yerleşik keşif, buluş ve anlayışları alt-üst eden internet teknolojisinde yaşanan bu gelişmeler sayesinde toplumsal yaşamı oluşturan tüm sosyal, kültürel ve ekonomik ilişkiler ve süreçler yeniden yapılandırılmaya ve aynı zamanda yeniden tanımlanmaya başlamıştır (Wenger, ve Snyder, 2000: 138; Kuyucu, 2015: 148).

Böylelikle siber dünyaya özgü yeni kavramları olan "siber kültür", "ağ toplumu", "sosyal ve ekonomik ağlar" gibi yeni kavramlar literatürdeki yerini almaya başlamıştır. Özellikle internet üzerinden kullanılan sosyal iletişim araçlarının küresel düzeyde yaygınlaşması sayesinde gerçek hayatta var olan "kültür" olgusunu oluşturan tüm temel öğelerin yapısı anlamı ve esaslı bir şekilde değişmeye başlamıştır. Bu yeni olgunun temelini bir sözcük ile açıklamak istenildiğinde ise seçilmesi gereken en bütünleyici ve genelleyici kavram "Siber kültür" kavramı olduğunu söylemek mümkündür (Colombain, 1997: 3-4; Lévy, 2001: 11).

Literatürde özellikle 1990'ların ortasından itibaren yaygın bir şekilde kullanılmaya başlanan bu yeni kültür biçimi için “internet kültürü" (Castells, 2001:7-8), "sanal kültür" (Jones, 1998: 14) ve "dijital kültür" şeklinde isimlendirilmelerin sıklıkla yapıldığı bilinmektedir (Bell, 2001:13). Siber kültür kavram1, internet aracılığıyla kurulan ve gün geçtikte gelişen bilgi ve iletişim teknolojilerinin ortaya çıkardığı "ağ toplumlarında" yaşayan insanların sahip olduğu yeni değer, tutum, davranış, norm ve inançlardan oluşan yeni bir sanal kültür çeşididir (Rheingold, 1993: 5). O yüzden kavramın kısaca, "internet âleminin kültürü" şeklinde de tanımlanması mümkündür (Bookchin, 1996: 10).

Literatürde yer alan bu tanımlara bakarak, siber kültür kavramını, internet sayesinde kurulan evrende yaşayan birey ve toplulukların geliştirdiği, somut yaşama sürekli etki eden ve sınırları sürekli gelişen ve değişen bir yaşam tarzı olduğunu söylemek mümkündür. Şüphesiz internet teknolojisinin bazı üstün özellikleri sayesinde iletişimin her türlüsünü kolaylaştırarak sosyal yaşantıda ve insan davranışları üzerinde yeni bir kültürel katman yaratma özelliğini baskın bir şekilde sergilemektedir (Timisi, 2003: 14). 
Ancak siber kültürün, milyonlarca insanın sıkılıkla internete girerek, sadece internette gezinmeleri sonucunda ortaya çıkan bir moda ya da alışkanlık olduğu söylenemez (Weinreich 1997: 5). Zira bu kültürün en önemli özelliği mekândan, zamandan ve gerçek hayattan bağımsız olarak, insanların/grupların "sosyal ve ekonomik ağlar" üzerinden birbirleriyle ilgi duydukları her türlü kültürel ya da ekonomik alanlarda paylaşmalarda bulunmalarına olanak vermekte ve bu sayede küresel düzeyde insanların tutum, davranış ve inançları değişerek benzeşmektedir (Subaş1, 2005: 110).

Ayrıca siber kültürde zaman, mekân ve bedensel sınırlılıkları internet üzerinden kurulan sosyal ve ekonomik ağlar aracılığıyla aşılmaya başlanmış ve sayılan kısıtlılıklardan bir anlamda kurtulan insanların tutumları, birbirleriyle ilişkileri ve çeşitli sosyal davranışları son derece değişken ve akışkan hale gelmiştir (Rab, 2007: 18; Paker, 2007: 125). Nitekim internet teknolojilerini bilgi çağının "çocuğu" olarak gören Johnny Ryan'e (2010: 11) göre internet teknolojisinin getirdiği değişim ve dönüşümler sınırsız sosyal ve ekonomik ağlar boyunca uzanmış çok sayıda ilişki ve etkileşim anlık olarak bir arada yaşanmak suretiyle yeni bir kültürel yaratmıştır.

Her ne kadar siber kültür teknolojik yazılımlardan türediği ve insanlarda sadece bilişsel anlamda farklılıklar yarattığ söylense de, bu kültür içinde doğan ve internetsiz bir dünyay hiç görmemiş genç nesiller açısından bu kültürün artık küresel düzeyde yerleşik hale geldiği çok rahatlıkla söylenebilir. Ayrıca günümüzde siber kültüre özgü kalıplar, büyük bir hızla gerçek hayatta da somut tavır, tutum ve davranışlara dönüşmektedir ve böylece siber kültür postmodern dünyanın ve bilişim çağının sürekli zenginleşen kültürü olarak sınırlarını ve kapsamını sürekli geliştirmektedir (Kuyucu, 2015: 148).

Her geçen gün siber uzamın sınırları genişledikçe bu yaşam formundaki bireylerin ve toplumların davranış kalıplarına göre şekillenen siber kültürün de kapsamı, içeriği, normları ve değerleri değişmekte, dönüşmekte, farklılaşmakta ve gelişmeye devam etmektedir. Şüphesiz bu durum hem insanların tüketim kültürünü hem de işletmelerin üretim sistemlerinin de yeniden yapılandırılmasını gerekli kilmaktadir.

İşte bu durum yeni ortaya çıkan ağ toplumlarında yaşayan bireylerin tüm sosyal ve ekonomik ilişkilerinin yepyeni davranış pratiklerinden oluşmasına, tüm sektörlerdeki tüketim tercih ve eğilimlerini değişmesine neden olduğunu söylemek mümkündür. Dolayısıyla denilebilir ki, sanal uzamda yaşanan gelişme ve ilerlemeler bir yandan siber kültürün gelişmesini ve yeniden yapılanmasını sağlarken, diğer yandan da yaşadığımız somut dünyada bu kültürü paylaşan bireylerin tüm geleneksel tüketim eğilim ve tercihlerini değiştirmektedir.

O nedenledir ki, günümüzde tüm sektörlerde artık geleneksel çizgide üretim yapan işletmeler artık siber kültürün ortaya çıkardığı yeni ekonomik düzeninin gerekli kıldığı çizgide üretim etkinliklerini ve üretim sistemlerini yeniden yapılandırma zorunda kalmaya başlamıştır. Zira artık siber kültürü benimseyen yeni tüketicilerin yeni tercih ve eğilimleri bulunmaktadır ve bunlar geleneksel çizgiden oldukça farklı içerik ve özellikler taşımaktadır.

\subsection{A Ağ Toplum Modelinin Doğuşu ve Gelişimi}

21. yüzyıl toplumlarının kültürel oluşumunda öne çıkan en önemli gelişmeler olarak literatürde sayılan küreselleşme, post-modernizm, post-fordizm ve internetin keşfi gibi gelişmeler aslında sadece sanayi toplum modelinden "bilgi toplum modeline" geçişi değil; aynı zamanda "bilgi toplum modeline göre birkaç tik önde ve ilerde olan, hatta "bilgi toplum modelinin" birkaç üst versiyonu olan "ağ toplum modeline" dönüşümün yolunu açmıştır (Castells 2010: 40).

A $\breve{g}$ toplum kavramını ilk ortaya atan Manuel Castells'e göre bu toplum yapıs1, 20. yüzyılın sonlarına doğru yeniden yapılandırılan endüstriyel üretim anlayışları küreselleşmeyle birlikte gelişen uluslararası ticari ilişkilerle somutlaşmış ve hakkında pek çok çalışma yapılan bir araştırma alanı olarak görülmeye başlanmıştır (Timisi, 2003: 149).

İşte böylesine önemli olan "ağ toplumu” küreselleşerek ulusal sınırlarından kurtulan tüm insanların dünyayı sarmalayan siber ağlarla birbiriyle iletişime ve etkileşime geçtiği ve varlığını açıkça somut hayata yeni bir toplum modelidir (Castells 2010: 42). Bu anlamda siber uzayda yaşanan iletişim ve etkileşimlere göre şekillenen "ağ toplumu" internet üzerinden kurulan sosyal ağlar sayesinde oluşmakta ve tüm dünyada mevcut olan ulusal ve örgütsel kültürleri tamamen değiştirmektedir (Castells, 2013: 500501).

İnternet aracılığıyla oluşan ve gelişen ağ toplumundaki egemen faaliyetlerin tamamının internet üzerinden kurulan sosyal ve ekonomik ağlardan meydana geldiği ifade edilmektedir (Abercrombie ve Longhurst, 2007: 241; Castells, 2010: 3-17). Özellikle internet kullanımının küresel düzeyde gelişmesiyle birlikte, siber uzayda yaşayan bireyler, giderek daha fazla sanal ortamları gerçek(miş) gibi algılamasıyla ortaya çıkmaya başlayan bu toplumsal yaşam biçimi, benzer hızla reel yaşama da yansıyarak gelişimini sürdürmeye devam etmektedir (Castells, 2013: 437-438).

A ̆g toplumu düşüncesine göre siber uzayda sosyal ağlar üzerinden gerçekleşen sosyal ve ekonomik etkileşim, çok güçlü bir şekilde reel toplumsal yaşam kalıplarını yeniden şekillendirmektedir (Castells, 2010: 19. Castells, 2013: 437438). Ayrıca bu toplumsal yaşam modelinin sayıca çok fazla bütünleşmiş, yer ve zaman açısından yayılımının sınırı olmayan ve insanların somut yaşamına sosyal ve ekonomik anlamda etkileri bulunan verilerle desteklenen değerlerden oluştuğu söylenmektedir (Castells, 2005: 13).

Sonuç olarak günümüzde yaşanan enformasyon devrimi siber kültürle birlikte ağ toplumunu yaratmıştır. Öyleyse denilebilir ki, internette paylaşılan her yeni bilgi, sosyal ve ekonomik ağlarla çok hızlı bir biçimde yayılmakta ve toplumun yaşamında önemli bir yer edinerek, toplumsal düzeni ve işleyişi değiştirip şekillendirerek "siber kültürü" benimseyen insanlara özgü ağ toplum modelinin gelişmesine katk1 sunmaya devam etmektedir (Hemsley ve Mason, 2013: 168).

\subsection{Sosyal ve Ekonomik Ağların Doğuşu ve Gelişimi}

Sosyal ağlar sahip olduğu teknolojik üstünlükler sayesinde gönderici-alıc1, mesajı tüketen kitleler yerine, herkesin aynı anda hem mesaj gönderen hem de alan durumunda olduğu 
ücretsiz, görüntülü, eş zamanlı, kitlesel, interaktif ve sonsuz içerikte iletişim imkânını kullanıcılara sunmaktadır (Thompson, 1995: 11-14).

Literatürde bireylerin kendilerine ait bir profil oluşturabildikleri ve bu profili kimlerin görebileceğine dair sınırlandırmaları da kendilerinin yapabileceği, diğer bireylerle iletişim kurarken güncel olayları da takip edebileceği, yazı, fotoğraf, video gibi çeşitli paylaşımlar yaparak ortak ilgi, amaç ve değere sahip olan bireylerle gruplar oluşturup coğrafi sınırlardan uzak bir birliktelik kurabileceği sanal platformlar tanımlanmaktadır (Boyd ve Ellison, 2007: 212).

Çok genel olarak "internet tabanlı sosyal medya mecralarının tümünü” tanımlamak için de kullanılan sosyal ağ kavramı internet teknolojisinde son birkaç yılda yaşanan gelişmelerin sayesinde ortaya çıkmış ancak hızla gelişerek literatürdeki yerini almıştır. Bu anlamda sosyal ağların ortaya çıkmasında Web 2.0 internet teknolojisinin sağladığ 1 yeniliklerden olan, kullanıcıların içerik yaratabilme, yaratılan içeriği başkalarıyla paylaşabilme ve milyonlarca kullanıcının karşılıklı olarak ağlar üzerinden eş anlı olarak etkileşimde bulunmasına imkan veren araçlardan oluşması sağlamıştır (Dolgun, 2008: 201).

Siber kültürde gelişen yeni toplumsal iletişim kanallarının içine taşındığ 1 alternatif ve küresel düzeyde bir kamu ortamına dönüşen sosyal ağlar, internet teknolojisinde yaşanan gelişmeler paralelinde zenginleşmekte ve büyümektedir. $\mathrm{O}$ nedenle sosyal ağların varlığından bahsederken, belli bir teknolojik araçlar grubundan ziyade, mobil iletişim araçlarıyla desteklenen sosyal medya uygulamalarına atıf yapılmaktadır (Kaplan ve Haenlein, 2010: 61).

Zira ağ toplum modelinin de ortaya çıkmasını sağlayan sosyal ağların hem sosyal iletişim hem de ekonomik etkileşim boyutlarını ortaya koyan platformlar aslında "sosyal medya platformları" ya da "sosyal paylaşım ağları" şeklinde tanımlanan çeşitli web siteleri oluşturmaktadır (Altunay, 2010: 14-16). Birer küresel işletme olan sosyal paylaşım siteleri özellikle internet teknolojilerinde web 2.0 araçlarının gelişmesiyle bambaşka bir döneme girilmiş ve büyük bir hızla yeni toplumsal düzenin ilk adımları "sosyal medya" çatısı altında atılmaya başlanmıştır (Karal ve Kokoç, 2010: 252).

Sosyal medya siteleri sayesinde dünya genelinde ve tüm toplumlardaki yerleşik iletişim anlayışları alt-üst olmuş, bu sitelerde ücretsiz olarak tüm insanların kullanıma sunulan internet olanakları sayesinde sosyal ve ekonomik yaşama ilişkin tüm değerlerde değişim ve dönüşümler yaşanmaya başlamıştır. Özellikle 2004 yılından itibaren kullanılmaya başlanan ve ikinci nesil internet devrimi olarak da adlandırılan yeni ağ teknolojisi, internet ortamında sosyal paylaşım ağlarının gelişmesine öncülük ederek, "sosyal medya", "sosyal ağ" ve "sosyal network siteleri" ile tüm dünyanın çepe çevre kuşatılmasına olanak sağlamıştır (Kuyucu, 2015: 146-147).

Dünyada yaşayan insanlarının yaklaşık üçte birinin, hem sosyal hem de mesleki yaşamlarında önemli yer edinen sosyal ağların kullanıcılarının sayısı her geçen gün artmakta, bu artış beraberinde ekonomik ilişkilerin de bu mecralar üzerinden geliştirilmesinin yolunu açmaya başlamıştır
(Tosun, 2010: 388). Örneğin eskiden sanatsal becerisini bile pazarlama konusunda sorun yaşayan bireyler, sosyal paylaşım ağları vasıtasıyla bir anda ortaya koyduğu sanatsal eserini 7 milyar insanın beğenisine sunma olanağını kazanmakta ve böylece takdir edilen ya da paha biçilemeyen bir yeteneği olan sanatçıların keşfedilmesi sadece birkaç dakika sürmektedir (Pittman ve Reich, 2016: 159).

İşte bu tür değişim ve dönüşümler öylelikle sosyal ağların ekonomik ağlara dönüşümüne yol açmıştır. Zira günümüz insanları artık, bir yandan sanal uzamda yaşadıkları deneyim ve gerçeklikleri somut yaşamlarının bir parçası haline getirirken, diğer yandan da sosyal sermayelerini (dijital habitus) sosyal ağlar üzerinden girdikleri ilişki ve paylaşımlarla geliştirmektedirler.

Özellikle internet kullanımının küresel düzeyde gelişmesiyle birlikte, siber uzayda yaşayan bireyler, giderek daha fazla ekonomik anlamda reel yaşamlarının çeşitli ihtiyaçlarını sosyal ağlar aracılığıyla gidermeye başlamıştır. Siber kültürü benimseyerek sosyal sermayelerini her geçen gün geliştiren ağ toplumuna mensup bireylerin siber evrende edindikleri alışkanlık, tutum ve eğilimlerinin değişmesi ise ekonomik yaşamın her sektöründeki işletmelerin geleneksel üretim kalıplarını yeniden şekillendirmesini zorunlu kılmaktadır.

İşte bu yüzden siber kültürü benimseyen ağ toplumlarında faaliyet gösteren işletmeler, her gün yeni bir sosyal ağ uygulamasıyla zenginleşen ve genişleyen yeni ekonomik sistemde değişen müşteri talep ve beklentilerine göre yeni üretim, yönetim, pazarlama vb stratejiler geliştirmeye başlayarak sosyal ağların ekonomik ağlara dönüşmesinin yolu açılmıştır (Kaplan ve Haenlein, 2010: 61). Diğer bir deyişle sosyal ağlar artık ekonomik ağlarla birleşerek iç içe geçmiş, böylece geleneksel ekonomik sistemin baştan sona ağ odaklı yeniden yapılanmasına neden olmuştur.

Sonuç olarak neo-liberal küresel ekonomik sistemde sosyal ağ kullanıcı sayılarının milyonlarla ifade edilemeye başlamasıyla birlikte rekabet üstünlüğü arayışı içerisindeki tüm üreticiler ve işletmeler sosyal ağlara olan ilgisi artmış böylelikle "ekonomik ağlar" "sosyal ağlara" eklemlenerek "sosyal ekonomik ağlar" olarak tanımlanan yeni endüstriyel alanlar açılmıştır. $\mathrm{Bu}$ nedenledir ki günümüzde sosyal ekonomik ağlarda, stratejik yaklaşımlarla üretim, pazarlama, reklam ve diğer yönetsel uygulamalar geliştirmek günümüz işletmeleri açısından rekabet üstü olmanın en etkili yolu haline gelmiştir.

\subsection{Yönetsel Stratejilerin Oluşturulmasında Sosyal Ekonomik Ağların Önemi}

Günümüzde etkili yönetsel stratejiler geliştirmenin ön koşulu yeni ekonomik sistemi, internet üzerinden gerçekleşen ticareti ve bir bütünlük içerisinde siber kültürü, ağ toplum modelini ve sosyal ekonomik ağların karakteristik özelliklerini çok yakından tanımayı gerektirmektedir (Ryan, 2010: 11). Zira internet ve bilgi teknolojilerinde yaşanan baş döndürücü gelişmeler artık yeni toplum modelleri ve yeni tüketim alışkanlıkları yaratmaya başlamıştır (Castells, 2013: 437-438).

A $\breve{g}$ toplum modeli olarak nitelenen yeni toplumsal düzlemde, müşteri ve tüketicilerin artık iletişim ve tüketim biçimleri değişmiştir (Castells, 2010: 19). Asıl önemlisi ise geleneksel ekonomilerde yüzyıllardır benzer şekilde 
tanımlanan satış, talep, arz, fiyat, pazarlama ve benzeri kavramlarla ilgili tüm kuramlar yeni ortaya çıkan "sosyal ve ekonomik ağlar" içerisinde anlam ve önemini kaybetmeye başlamıştır (Hemsley ve Mason, 2013: 168; Pittman ve Reich, 2016: 158).

Sınırsız sayı ve içerikteki iletişim olanaklarıyla "ağların ağı" olarak nitelenen internet üzerinden kurulan sosyal ilişkiler küresel düzeyde yoğunlaştıkça, bu ağlar tüm işletmelerin en önemli üretim, tanıtım, satış, pazarlama ve fiyatlama platformu haline dönüşmekte ve ekonomik ağların sosyal ağlara eklemlenerek daha da genişlemesinin yolu aç1lmaktadır (Avc1, 2015: 248-249).

Eskiden sanatsal becerisini bile pazarlama konusunda sorun yaşayan bireyler, sosyal paylaşım ağları vasıtasıyla bir anda ortaya koyduğu sanatsal eserini 7 milyar insanın beğenisine sunmakta ve takdir edilen ya da paha biçilemeyen bir yeteneği olan insanların keşfedilmesi ise sadece birkaç dakika sürmektedir (Pittman ve Reich, 2016: 159).

Gerçekten de günümüzde insanlarının yaklaşık üçte birinin, hem sosyal hem de mesleki yaşamlarında önemli yer edinen, sosyal paylaşım sitelerinin sayıları her geçen gün artmakta, bu artış beraberinde daha fazla kullanıcıyla desteklenen yeni sosyal ağların ortaya çıkmasına yol açmaktadır (Tosun, 2010: 388). Örneğin 2004'de kurulan Facebook, 2015 y1lı Mart ayı itibariyle aylık 1.4 milyar aktif kullanıcısı ve günlük 936 milyon aktif kullanıcısı olan bir sosyal paylaşım ağı haline gelmiştir (Chua ve Chang, 2016: 190).

Facebook'tan kısa bir süre sonra kurulan Twitter 302 milyon kullanıcısının günde ortalama 500 milyon tweet yazdığı başka bir popüler sosyal ağdır (Chua ve Chang, 2016: 190). Ayrıca sosyal ağlar üzerinden toplam dünya nüfusunun nerdeyse üçte birinin her gün birbirleriyle aktif sosyal ilişki kurduğu ve günde ortalama 2 saat 25 dakika bilgi ve içerik paylaştığı da bilinmektedir (Hazar, 2011: 154-155).

Sosyal ağların Türkiye'deki gelişimi ile anlam ve önemini gösteren istatistiklere bakıldığında bazı rakamlar oldukça fazla dikkat çekmektedir. Örneğin Google tarafından 2013 yılında yaptırılan ve toplamda kırk altı ülkenin yer aldığ "Tüketici Barometresi" araştırması sonucunda Türkiye, sosyal paylaşım ağlarını kullanım oranı yüzde 92'lik oranla diğer 45 ülkeden yüksek çıkarak 1.sırada yer almıştır (Hemsley ve Mason, 2013: 168).

Aynı araştırma sonucunda Türkiye'de interneti yüzde 84 oranında en çok kullanan kesimin, 16-24 yaş grubundaki gençler olduğu tespit edilmiştir. Benzer şekilde TÜİK verilerine göre Türkiye'de en çok bilgisayar ve internet kullanan kesim 16-24 yaş grubudur ve bu genç yaş grubunun kişisel amaçla internette yaptıkları faaliyetlerin sıklığı sıralamasında sosyal ağlara (facebook, twitter vb.) katılım ilk siradadir (TUİK, 2015).

$\mathrm{Bu}$ verilerden anlaşılacağı üzere günümüzde artık internet tüm dünya insanları tarafindan hem sosyal hem de ekonomik yaşamda sıklıkla kullanılmaktadır. Özellikle internet üzerinden kurulan sosyal ağlar, her geçen gün çeşitlenmeye ve zenginleşmeye devam ettikçe, bu ağlar artık gündelik yaşamda ekonomik ve ticari amaçlarla yoğun bir şekilde kullanılmaya devam başlanmıştır. İşte günümüzde tüm işletmeler, yatırımcılar ve üreticiler bu yüzden marka kimlikleriyle sosyal ağlarda boy göstererek, pazarlamadan müşteri ilişkileri yönetimine kadar geniş bir yelpazede tüm örgütsel süreçlerini sosyal ağların üzerinden tanıtmaya ve pazarlamaya başlamışlardır (Avcı, 2015: 253).

Bir anda milyonlarca müşteriye sıfir maliyetle ulaşma imkânı bile veren sosyal ağların bu potansiyeli küresel çaptaki organizasyonların dikkatini çektiği kadar.-belki de onlardan daha fazla oranda- KOBİ'lerin dikkatini çekmektedir (Pittman ve Reich, 2016: 162). Ayrıca firmalarının, hizmetlerinin ve yeteneklerinin tanıtımını ve pazarlamasını görsel ve işitsel reklam araçlarının hepsini ücretsiz bir şekilde, sınırsız sayı ve sıklıkta kullanma olanağı sunan sosyal ağlar sayılan nedenlerle ekonomik ağlarla ayrılmaz bir şekilde iç içe geçerek küresel düzeyde yaygınlaşmıştır (Gere, 2008: 6; Toprak vd., 2009: 105).

Zira sürekli değişim ve gelişimden yana olan stratejik yönetim anlayışının en önemli önceliği, işletmeleri yeni ortaya çıkan ekonomik ve sosyal ağlarda rekabet üstü olmasını sağlayacak düzeyde etkili yönetsel stratejiler geliştirmektir (Narinoğlu, 2009: 122).

Ayrıca stratejik yönetimin geleceği öngörmeye çalışan perspektifi, işletmelere ekstradan rekabet avantajı yaratması ve ortalama üzerinde getiriye odaklanarak bütüncül bakış açısıyla olaylara yaklaşması ekonomik ve sosyal ağlara bu anlayışın odaklanmasının önemini daha da arttırmaktadır (Söyler, 2007: 105). Zira gerek sistem gerekse durumsallık yaklaşımlarına göre yönetsel stratejiler oluşturulurken doğrudan doğruya gelecek öngörülerinin ve çevresel değişimlerin dikkate alınması buna göre işletmelerin açık sistem özelliklerini korunması ve çevresel değişmelere göre yeni yönetsel stratejilerle zamana ayak uydurulması gerekmektedir.

İşletmeler strateji oluştururken ağ toplumlarına mensup bireylere özgü sosyal ve ekonomik ağları çok yakından takip ederek bu tür ağlarda yaşanan değişim ve gelişmelere göre yönetsel süreçlerini yapılandırmalı ve strateji geliştirmelidirler. Zira geleceğin belirsizlik ve tehditlerinden işletmeleri koruyarak, gelecekte ortaya çıkacak firsatları önceden görebilmek yalnızca böyle mümkün olacağ 1 söylenebilir.

Yönetsel strateji oluşturma açısından sosyal ekonomik ağların anlam ve önemini gösteren diğer bir konu da stratejilerin "gelecek odaklı" bir anlayışla planlanması aşamalarında kendini göstermektedir. Zira stratejik planlar oluşturulurken işletmenin geleceğine yön vermek amacıyla bugünün çevresel koşulları ile mevcut müşterilerin tüketim eğilimlerine göre işletmenin gelecekteki üretimi tasarlanmaya çalışılır (Narinoğlu, 2009: 207).

Özellikle strateji geliştirme aşamasında örgütün dış ve iç çevresi ile tüm paydaşları hakkında daha sistemli bilgiler toplanır, bunları sistemli bir şekilde analiz edilir, değerlendirilir ve tüm çalışanlarla paylaşılarak örgütsel öğrenmenin yaşam boyu artmasının ve örgütün gelecekteki yönünün belirlenmesi sağlanır (Demirdizen, 2012: 4).

Şüphesiz hangi sektörde olursa olsun günümüzde işletmelerin geleceğe yönelik stratejiler geliştirirken en sağlıklı ve güvenilir verileri toplayacakları mecralar sosyal ve ekonomik ağlardır. Bu açıdan ağlardan toplanan müşteri, sektör ve trendlere ilişkin veriler strateji oluşturma sürecinde kullanılan analizler güvenilir, sağlıklı, etkili ve gelecek 
odaklı bulgulara ulaşılmasını sağlayacak ve bu sayede işletmeler geleceği bugünden tasarlayabileceklerdir.

Strateji geliştirme sürecinde sosyal ekonomik ağların anlam ve önemini ortaya koyan bir diğer konu da strateji geliştirme süreçlerinin çalışanların katılımına dayalı, müşteri-kalite odaklı, sürekli iyileştirmeyi temel alan, son derece dinamik ve değişim-dönüşümlere göre şekillenen yönetsel bir zeminde gerçekleşmesinden kaynaklanmaktadır (Bayrak, 2013: 23). Bu açıdan işletmenin günümüzde kaliteli mal veya hizmet üretmek amaciyla oluşturduğu tüm stratejiler sosyal ve ekonomik ağlara göre şekillenmelidir. Zira kalite anlayışı sadece örgütlerin rekabet gücünü arttırmamakta, toplumlarda yaşam düzeyini ve yaşam standartlarını da olumlu yönde etkilemektedir.

Sonuç olarak kalite günümüz ağ toplumlarında siber kültürü benimseyen tüm insanların artık yaşam tarzı olmuştur. $\mathrm{O}$ nedenle sosyal ve ekonomik ağlara odaklanarak müşteri beklentilerine uygun ürün ve hizmetlerin ortaya konulması, bir yandan müşteri değer artışı sağlarken diğer yandan da satışları arttıracak, maliyetleri azaltacak ve kârlılık üzerinde olumlu etkiler sağlayacaktır (Efil, 2011: 78).

\section{Sonuç ve Öneriler}

Küreselleşme ve internet teknolojilerinde yaşanan gelişmeler sayesinde önceleri bilgi toplumları ve bilgi ekonomileri ortaya çıkmış, ancak gelinen son noktada internet sayesinde siber evren keşfedilmiş ve böylece "ağ toplumu modeli" ve bu toplumun benimsediği "siber kültür" ortaya çıkmıştır.

Siber evrende yaşayan ağ toplumlarının sahip olduğu siber kültür bir yandan küreselleşmeyi güçlendirirken, ortaya çıkan sinerji sayesinde gittikçe güçlenen küreselleşme de sosyal ve ekonomik ağlara dayalı yeni bir ekonomik sistemin ortaya çıkmasının yolunu açmıştır.

Yeni ortaya çıkan ekonomik sistemde, siber kültürü benimseyen ağ toplumlarında yaşayan günümüz tüketicilerine yönelik üretim ve satış yaparak faaliyetlerini devam ettirmek isteyen tüm işletmeler, öncelikle yaşanan değişim ve dönüşümleri stratejik açıdan ele almalı ve ağlar üzerinden elde ettiği verileri kapsamlı analizlere tabi tutarak geleceğe kendini hazırlamaya çalışmalıdır.

Zira siber kültürü benimseyen ve ağ toplum modeline göre yaşamlarını sürdüren milyonlarca insanın, artık tüketim tercih ve alışkanlıklarını belirleyen en önemli değişkenlerin neler olduğuna dair ipuçlarını sosyal ağlarda açık bir şekilde ifade etmektedir. Onların sosyal sermayelerine göre şekillenen çizgide, sosyal ekonomik ağlarda edindikleri deneyimlere ve küresel standartlara göre üretim süreçlerini yapılandırmayan işletmelerin ise artık ayakta kalması mümkün değildir.

İşte bu yüzden pazarlamadan rekabete ve girişimciliğe kadar her yönetsel alanda strateji geliştirilirken, öncelikle siber kültürü benimseyen ağ toplumlarının sürekli bilgi ve deneyimlerini geliştirdikleri sosyal ve ekonomik ağlar mercek altına alınmalı; buralarda yer alan paylaşımlara göre müşteri beklenti ve şikâyetleri tespit edilerek strateji oluşturma süreçlerinde dikkate alınmalıdır.

$\mathrm{Bu}$ noktada, temel amacı yönetsel stratejilerin oluşturulmasında sosyal ekonomik ağların önemine işletmelerin ve yöneticilerin dikkatlerini çekmek olan bu araştırma sonucunda ulaşılan bulgulara göre bazı önerilerde bulunmak mümkündür.

İlk olarak söylenmelidir ki, kullanıcı sayıları nerdeyse dünya nüfusunun yarısına yaklaşan sosyal ekonomik ağlar artık müşteri beklentilerinin, eğilimlerinin, tercihlerinin ve şikâyetlerinin en sıklıkla tartışıldığı müşteri ilişkileri yönetim platformları haline dönüşmüştür. $O$ nedenle günümüz işletmeleri müşteri beklenti ve taleplerine ilişkin en kapsamlı bilgi, veri ve talepleri bu mecralardan toplayarak ona göre pazarlama, tanıtım, üretim vb. stratejiler geliştirmelidirler.

İkinci olarak, günümüzde artık sanayi ötesi toplumlardan ya da bilgi toplumlarından öte ağ toplum modeline geçildiği göz önünde tutulmalıdır. Siber kültürü benimseyen bu toplumsal yapıya mensup insanlar işletmelerin hem insan kaynaklarını hem de müşterilerini oluşturmaktadır. Öyleyse insan kaynakları yönetiminden pazarlama ve üretim yönetimine ilişkin alınacak tüm stratejik kararlarda sosyal ve ekonomik ağlardan beslenen siber kültürü oluşturan yeni değerler, normlar, tutumlar, inançlar ve davranışlar çok iyi tespit edilerek stratejiler geliştirilmelidir.

Son olarak işletmelerin sistemli bir şekilde strateji geliştirmelerine olanak sağlayan stratejik yönetim ve stratejik planlama süreçlerinde işletme vizyonu, misyonu, amaçları, hedefleri ve hatta çevresel değişim analizleri yapılırken sosyal ve ekonomik ağ odaklı anlayış ve uygulamalara yer verilmesi gerektiği söylenmelidir.

Böylece stratejik yaklaşımların temel hedeflerine ulaşması mümkün olacak ve işletmelerin geleceğini planlamaya, etkili üretimler gerçekleştirmelerine ve karlılığını arttırmaya olanak sağlayan strateji oluşturma uygulaması başarılı olacaktır.

\section{Kaynakça}

Abercrombie, N., \& Longhurst, B. (2007). Dictionary of Media Studies. London: Penguin Books.

Acar, E. (2007). Yarı Resmi Bir Örgütte Stratejik Planlama Uygulamast: Aydın Ticaret Odast Örneği. Yayınlanmamış Yüksek Lisans Tezi. Aydın: Adnan Menderes Üniversitesi.

Akgemici, T. (2015). Stratejik Yönetim. Ankara: Gazi Kitabevi.

Altunay, M. C. (2010). Twitter: Gündelik Yaşamın Yeni Rutini Plt Net. 6. Eskişehir: Anadolu Üniversitesi, Eskişehir.

Avcı, Ö. (2015). Dijital Yaşamın Dijital Özne(l)leri: Herkes ya da Hiç Kimse. Uşak Üniversitesi Sosyal Bilimler Dergisi, 8(1), 248-266.

Aydemir, S. (2011). Aile İşletmelerinde Yöneticilerin Stratejik Yönetim Ve Planlamaya İlişkin Alglarının Incelenmesi: Zonguldak-Bartın-Karabük Bölgesi Örneği. Doktora Tezi. Zonguldak: Bülent Ecevit Üniversitesi.

Aydın, M. D., \& Aksoy, S. (2007), Kamu Kesiminde Stratejik Planlama Ve Çalışanlara Yansıması: Hacettepe 
Üniversitesi Örneği. Hacettepe Üniversitesi İktisadi ve Idari Bilimler Fakültesi Dergisi, 25(1), 293-322.

Barca, M., \& Hizıroğlu, M. (2009). 2000’li Yıllarda Türkiye'de Stratejik Yönetim Alanının Entelektüel Yapısı. Eskişehir IİBF Dergisi, 1(4), 110-119.

Barca, M., \& Nohutçu, A. (2008). Кати Yönetiminde Çă̆daş Yaklaşımlar. Ankara: Seçkin Yayınları.

Bayrak, A. (2013). Belediyelerde Stratejik Yönetim Ve Faaliyetlerin Önceliklendirmesine Yönelik Bir Model Önerisi. Yüksek Lisans Tezi. Bursa: Uludağ Üniversitesi.

Bayraktar, B. B., \& Yıldız, A. K. (2007). Kurumsal Bilginin Stratejik Planlama Sürecinde Kullanılması: Bir İlçe Belediyesi Örneği. Bilgi Dünyası, 8(2), 280-296.

Bell, D. (2001). An Introduction to Cyberculture. New York: Routledge Pub.

Bhatt, G. D. (2001). Knowledge management in organizations: examining the interaction between technologies, techniques, and people. Journal of Knowledge Management. 5(1), 68-75.

Bookchin, M. (1996). Ekolojik Bir Topluma Doğru. Abdullah Yılmaz (Çev.). İstanbul: Ayrıntı Yayınları.

Boyd, D. M., \& Ellison, N. B. (2007). Social Network Sites; Definition History and Scholarship. Journal of Computer Mediatedm Comminication. 13(1), 210-230.

Buzlu, V. (2014). Stratejik Yönetim, Planlama ve Sağllk Sektörü. İstanbul: Sistem Yayınları.

Castells, M. (2001). The Internet Galaxy:Reflections on the Internet, Business and Society. Oxford: Oxford University Press.

Castells, M. (2005). A ̆g Toplumunun Yükselişi, Enformasyon Çağı: Ekonomi, Toplum Kültür. İstanbul: İstanbul Bilgi Üniversitesi Yayınları.

Castells, M. (2010). Enformasyon Çă̆l: Ekonomi, Toplum ve Kültür. Cilt 2: Kimliğin Gücü. Ebru Kılıç (Çev.). İstanbul: İstanbul Bilgi Üniversitesi Yayınları.

Castells, M. (2013). The Network Society: A Cross Cultural Perspective. Northampton: Edward Elgar Publishing Limited.

Chua, T. H. H., \& Chang, L. (2016). Follow me and like my beautiful selfies: Singapore teenage girls'engagement in self- presentation and peer comparison on social media. Computers in Human Behavior. 55(A), 190-197.

Colombain, J. (1997). Siber Kültür. (Çev. Bülent Küçükerdoğan). İstanbul: İstanbul Üniversitesi.

Çevik, H. H. (2010). Kamu Yönetimi, Kavramlar, Sorunlar, Tartışmalar. Ankara: Seçkin Yayınları.

Çiftçi, T. (2011). Üç Adımda Stratejik Yönetim, İstihbaratIstikamet-İcraat. İstanbul: İstanbul Sanayi Odası Yayınları.

Dalmış, A. B. (2014). Türkiye’de Ticari Hava Taşımacılık Sektörünün Strateji Belirleme Sürecinde SWOT Analizinin Rolü: Tasarım Okulu Perspektifiyle Bir
Inceleme. Yüksek Lisans Tezi. Ankara: Türk Hava Kurumu Üniversitesi.

David, F. R. (2005). Strategic Management: Concepts and Cases. New Jersey: Pearson Prentice Hall.

Demirdizen, Ö. (2012). Stratejik Planlama, Stratejik Planlama Süreci, Hukuki Altyapısı ve Kamuda Gelişimi. Akademik Bakış Dergisi. 3(31), 31.

Dinçer, Ö. (2013). Stratejik Yönetim ve İşletme Politikası. İstanbul: Alfa Basım Yayım Dağıtım Ltd Şti.

Doğan, H. (2008). Örgütlerde Vizyon Ve Misyonların Çalışanlarca Kabulü ve Adnan Menderes Üniversitesi Örneği. Gazi Üniversitesi İktisadi ve İdari Bilimler Fakültesi Dergisi. 10(3), 93-110.

Dolgun, U. (2008). Şeffaf Hapishane yahut Gözetim Toplumu. İstanbul: Ötüken Yayınları.

Efil, İ. (2011). İsletmelerde Yönetim ve Organizasyon. İstanbul: Alfa Aktüel.

Eren, E. (2015). Işletmelerde Stratejik Yönetim ve Işsletme Politikası. İstanbul: Beta Basım Yayım.

Gere, C. (2008). Digital Culture, Second Edition. London: Reaktion Pub.

Güçlü, N. (2003). Stratejik Yönetim. Gazi Üniversitesi Gazi Eğitim Fakültesi Dergisi. 23(2), 61-85.

Gül, S. K., \& Kırılmaz, M. (2013). Kamu Kurumlarında Stratejik Yönetim. Ankara: Adalet Yayınevi.

Hazar, M. (2011). Sosyal Medya Bağımlılı̆̆ı: Bir Alan Araştırması. Gazi Üniversitesi Illetişim Fakültesi Dergisi. 2011 (32), 151-176.

Hemsley, J., \& Mason, R. M. (2013). Knowledge and knowledge management in the social media age. Research \& Policies 2013 (23), 168.

Jenkins, H., \& Thorburn, D. (2004). Democracy and new media. Cambridge: The MIT Press.

Jones, S. (1998). Virtual Culture: Identity and Communication in Cybersociety. CA: Sage Publications.

Kaplan, M. A., \& Haenlein, M. (2010). Users of the world, unite! The challenges and opportunities of Social Media Business. Horizons. 53 (1), 59-68.

Karal, H., \& Kokoç, M. (2010). Üniversite Öğrencilerinin Sosyal Ağ Siteleri Kullanım Amaçlarını Belirlemeye Yönelik Bir Ölçek Geliştirme Çalışması. Turkish Journal of Computer and Mathematics Education, 1(3), 251-263.

Koçel, T. (2011). İşletme Yöneticiliği. İstanbul: Arıkan Basım Yayın.

Kuyucu, M. (2015). Web 2. Haçlı Seferleri Twitter ile Ana Akım Medyanın Erişim Savaşı. İçinde: S. E. Karakulakoğlu \& Ö. Uğurlu (Ed.), İletişim Çalışmalarında Dijital Yaklaşımlar: Twitter içinde (s.145-181). Ankara: Heretik Basin Yayın.

Lévy, P. (2001). Cyberculture. Minneapolis: University of Minneapolis Press.

Murat, G., \& Bağdigen, M. (2008). Kamu İdarelerinde Stratejik Planlama ve Yönetim. Ankara: Gazi Kitabevi. 
Narinoğlu, A. (2009). Yerel Yönetimlerde Stratejik Planlama ve Uygulama. İstanbul: Mart Matbaacılik.

Nohutçu, A. (2008). Yerel Yönetimlerde Stratejik Plan Uygulama Girişimleri. 1. Ulusal Yerel Yönetimler Sempozyuти. Sakarya.

Özgür, H. (2004). Kamu Örgütlerinde Stratejik Yönetim. İçinden: M. Acar \& H. Özgür (Ed.), Çağdaş Kamu Yönetimi I. (s. 208-252). Ankara: Nobel Yayın Dağıtım.

Öztop, S. (2007): Stratejik Planlamanin Belediyelere Uygulanması. Yüksek Lisans Tezi. Kocaeli: Kocaeli Üniversitesi.

Paker, K. O. (2007). Iletişimin Fast Food'u: Sanal Diyarlarda Oyun, Chat ve Gizemli Yabancl, Medya Okumaları. Ankara: Nobel Yayıncılık.

Pittman, M., \& Reich, B. (2016). Social media and loneliness: Why an Instagram picture may be worth more than a thousand Twitter words. Computers in Human Behavior. 62(2016), 155-167.

Rab, Á. (2007). Digital culture - Digitalised Culture and Culture Created on A Digital Platform Information. Budapest: Coursebook.

Rheingold, H. (1993). The Virtual Community: Finding Connection in a Computerised World. London: Secker and Warburg Pub.

Ryan, J. (2010). A History of The Internet and The Digital Future. London: Rreaktion Books.

Söyler, İ. (2007. Kamu Sektöründe Stratejik Yönetim Uygulanabilir mi? Engeller/Güçlükler. Maliye Dergisi. $152,103-115$.

Subaşı, N. (2005). İnternet ve Sanal Cemaat Tartışmaları. İçinde: M. Binark \& B. Kılıçbay (Ed.), Internet, Toplum, Kültür. (s.106-117). İstanbul: Epos Yayınları

Şentürk, H. (2005). Belediyelerde Stratejik Planlama. İstanbul: İlke Yayınları.

Thompson, J. B. (1995). The Media and Modernity, Cambridge: Polity Press.

Timisi, N. (2003). Yeni Illetişim Teknolojileri ve Demokrasi, Ankara: Dost Yayınevi.

Toprak, A. (2009). Toplumsal Paylaşım Ăğ Facebook: Görülüyorum Öyleyse Varım!. İstanbul: Kalkedon Yayınları.

Tosun, B. N. (2010). İletişim Temelli Marka Yönetimi. İstanbul: Beta Yayınları.

TUİK (2015). Hane Halkı Bilişim Teknolojileri Kullanım Araştırması.. (Erişim: 15.06 .02017 ), http://www.tuik.gov.tr/VeriBilgi.do?alt_id=60

Ülgen, H., \& Mirze, K. (2013). Isşletmelerde Stratejik Yönetim, İstanbul: Literatür Yay.

Weinreich, F. (1997). Establishing a point of view toward virtual communities. (Erişim: 15. 06. 2017), http://www.december.com/cmc/mag/1997/feb/weinsen. html
Wenger, E. C., \& Snyder, W. M. (2000). Communities of practice: The organizational frontier. Harvard Business Review. January-February, 139-146. 